Revista "Política y Estrategia" No 130, 2017, pp. 125-149

ISSN 0716-7415 (versión impresa) ISSN 0719-8027 (versión en línea)

Academia Nacional de Estudios Políticos y Estratégicos

El rol de UNASUR ante los conflictos intraestatales en la Región

Alejandro Amigo Tossi

\title{
EL ROL DE UNASUR ANTE LOS CONFLICTOS INTRAESTATALES EN LA REGIÓN ${ }^{\circ}$
}

ALEJANDRO AMIGO TOSSI*

\section{RESUMEN}

El tratado constitutivo de UNASUR no contempla la prevención de conflictos, sin embargo, uno de sus objetivos es configurar un área de paz en Sudamérica y a partir de ese propósito, ha intervenido en una serie de conflictos que han amenazado la estabilidad de la región. Los casos han comprendido desde la estabilización de una crisis inter-estatal hasta un intento fallido de detener un juicio político de un presidente. Este artículo describe las circunstancias que configuraron los conflictos internos de Bolivia el 2008, Ecuador el 2010 y Paraguay el 2012; y el posterior rol de UNASUR en esas situaciones intraestatales.

Palabras clave: Conflicto; prevención de conflictos; estabilidad regional; Sudamérica; UNASUR.

\section{THE ROLE OF UNASUR IN INTRA-STATE CONFLICTS IN THE REGION}

\begin{abstract}
The UNASUR treaty does not consider the prevention of conflicts, however, one of its objectives is to create an area of peace in South America, and for that purpose, has intervened in a series of conflicts that have threatened the stability of the region. The cases have gone from the stabilization of an inter-state crisis to an unsuccessful attempt to stop a president's impeachment. This article describes the circumstances that shaped the internal conflicts of Bolivia in
\end{abstract}

Master of Arts in Security Studies, Georgetown University. Magíster en Conducción Militar, Academia de Guerra, Ejército de Chile. Licenciado en Ciencias Militares. Actualmente es Jefe de la Sección Planificación de Desarrollo Estratégico, Dirección de Operaciones del Ejército, de Chile. alejandroamigotossi@gmail.com Este artículo es parte de la investigación del mismo autor titulada, "El Rol de UNASUR en la prevención de conflictos", que ganó el Concurso de Investigación ANEPE 2017"; escrito que tendrá una segunda parte en el año 2018, que complementará las conclusions presentadas en este rabajo.

× Fecha de recepción: 200917 - Fecha de aceptación: 251017. 
2008, Ecuador in 2010 and Paraguay in 2012; and the subsequent role of UNASUR in those intra-state situations.

Key words: Conflict; conflict prevention; region stability; South America; UNASUR.

\section{INTRODUCCIÓN}

Los líderes de los países sudamericanos formaron la Unión de Naciones Suramericanas (UNASUR) en mayo de 2008. Esta organización regional tiene como objetivo profundizar la conexión entre las naciones sudamericanas, reconociendo sus intenciones similares, los activos sociales y los recursos energéticos ${ }^{1}$. Si bien el tratado constitutivo de UNASUR no articula la prevención de conflictos, la Unión ${ }^{2}$ ha intervenido en confrontaciones internas, disputas interestatales y controversiales decisiones soberanas de uno de sus miembros.

La primera intervención ocurrió en Bolivia en 2008, cuando el presidente y los líderes orientales del país se enfrentaron debido a una nueva constitución e intereses económicos. En este caso, los líderes de la Unión celebraron una Cumbre Presidencial en la que apoyaron el gobierno nacional, nombraron a un enviado especial para supervisar un diálogo político y se creó una comisión de investigación para investigar la violencia política. Posteriormente, en julio de 2010, UNASUR resolvió un impasse diplomático entre Colombia y Venezuela debido a las declaraciones del presidente colombiano Álvaro Uribe de que el gobierno venezolano apoyaba a grupos guerrilleros. La mediación del Secretario General de la organización contribuyó a resolver la situación entre esos países.

En septiembre de 2010, las fuerzas de policía ecuatorianas emprendieron un golpe de Estado fallido contra el presidente Rafael Correa, como respuesta a una nueva ley que afectaba sus intereses. UNASUR celebró una Cumbre Presidencial de emergencia que condenó el golpe de Estado y ordenó la concurrencia de todos los Ministros de Relaciones Exteriores a la capital de Ecuador para apoyar al gobierno nacional. La última intervención de UNASUR ocurrió en agosto de 2012 cuando el parlamento paraguayo acusó al presidente Fernando Lugo por gestionar de manera deficiente un incidente con muerte de civiles. Este hecho resultó en que una comisión de UNASUR compuesta por el Secretario General y los Ministros de Relaciones Exteriores se dirigiera a la capital paraguaya; sin embargo, no pudieron detener el proceso de destitución que ocurrió el día siguiente.

El propósito de esta investigación es sentar las bases para una discusión académica sobre el rol de UNASUR en la prevención de conflictos, mediante la descripción de las circunstancias que configuraron los conflictos internos de Bolivia el

www.unasursg.org. Fecha de consulta: abril 2017.

Se empleará como sinónimo de UNASUR. 
2008, Ecuador el 2010 y Paraguay el 2012; y el posterior rol de la Unión para estabilizar esas situaciones intraestatales. Las razones para seleccionar estos conflictos se refieren a características comunes de las situaciones internas y de la intervención de la Unión, como asimismo, al tiempo transcurrido de los casos. En primer lugar, en los tres casos analizados, confrontaciones en el ámbito de la política interna desencadenaron una escalada del conflicto entre dos bloques opuestos, que amenazó la estabilidad de esos países. En segundo lugar, son los casos en que UNASUR intervino en situaciones intraestatales hasta el año 2012; por tanto, no se consideran en este trabajo el análisis de conflictos de carácter interestatal donde ha actuado la organización regional. Finalmente, con el objetivo de considerar dentro de las fuentes de información, artículos académicos que hayan estudiado los casos seleccionados, no se considera en el análisis situaciones intraestatales posteriores al año 2012.

Por corresponder a un artículo de carácter descriptivo, no se ha considerado una hipótesis que requiera ser demostrada con la información sobre los distintos contextos nacionales que caracterizaron a los conflictos de Bolivia, Ecuador y Paraguay; y respecto a la acción de UNASUR en esos países. El contenido del trabajo se ordena de la siguiente manera; en primer término, se definen ciertos conceptos que serán utilizados en el trabajo y se revisa la literatura sobre prevención de conflictos. A continuación, se describen los antecedentes de la organización regional y una breve síntesis de su rol en la prevención de conflictos hasta el año 2012. Posteriormente, se relatan las principales circunstancias de las crisis internas y los antecedentes sobre el rol de UNASUR en Bolivia, Ecuador y Paraguay. A continuación, se desarrolla un breve análisis de los resultados del trabajo, respecto a los aspectos similares y diferentes de los conflictos internos y del rol de la Unión. Para finalizar, se concluye sobre el logro del objetivo y respecto al rol de la Unión en el ámbito de la prevención de conflictos.

\section{MARCO CONCEPTUAL}

Con el objetivo de precisar los conceptos que serán más adelante utilizados y sin el propósito de teorizar sobre los mismos, a continuación se describirán cada uno empleando como referencia las definiciones del Uppsala Conflict Data Program ${ }^{3}$. En primer lugar, la denominación de "actor" corresponderá al gobierno, que es funcional y mantiene el poder desde la capital del Estado, y a un grupo o grupos formalmente organizados al interior del país. Como tercer actor o solo "tercero", se entenderá a la parte que coopera para solucionar el conflicto y actúa como un intermediario.

3 www.pcr.uu.se/research/ucdp/definitions/ Fecha de consulta: mayo 2017. 
En segundo lugar, para denominar las confrontaciones internas se empleará el concepto de "conflicto", entendido este como una incompatibilidad o materia de discusión entre actores opuestos. Esta incompatibilidad puede ser sobre el gobierno o respecto al total o parte del territorio. En relación al gobierno, se refiere al tipo del sistema político (un solo partido, sistema multipartidista o monarquía a república), la sustitución del gobierno central o el cambio de su composición (miembros del gabinete, el primer ministro o el presidente). En cuanto a la incompatibilidad sobre el territorio, se refiere al control de un determinado territorio o la secesión o autonomía de una parte de este. Respecto al concepto de crisis, este no será empleado por corresponder a una de las etapas del conflicto $^{4}$, y la evidencia recopilada no permite determinar si las situaciones internas analizadas corresponden a esa fase; por ende, se empleará el término conflicto para los tres casos. Finalmente, el término intraestatal se refiere a una confrontación entre un gobierno y un actor interno no gubernamental, donde no existe interferencia de otros países.

\section{Prevención de conflictos}

La literatura sobre prevención de conflictos comprende principios fundamentales, tales como los tipos de prevención, la conveniencia de su aplicación temprana y la preponderancia que debiera poseer en las políticas de las instancias multilaterales en el ámbito de la seguridad. La clasificación general de las estrategias de prevención se compone de la prevención estructural, que aborda las causas subyacentes de potenciales conflictos, y la prevención operacional, que afronta las causas más próximas de los conflictos. Algunos académicos agregan la prevención sistémica, introducida por el Secretario General de la ONU en 1994, que busca reducir los conflictos a nivel global con mecanismos que no se centran en un Estado particular ${ }^{5}$.

Existen argumentos claros sobre las ventajas de la prevención de conflictos en lugar de intervenciones tardías para detener las conflagraciones que se han tornado violentas ${ }^{6}$. Asimismo, se concuerda que la prevención de conflictos debiera ser una prioridad en las políticas de Naciones Unidas, organizaciones regionales, gobiernos nacionales, organizaciones no gubernamentales y para los grupos de la sociedad civil $^{7}$.

4 LUND, Michael. Conflict prevention: Theory in pursuit of policy and practice. En: Bercovitch, Jacob "et al". Handbook of Conflict Resolution. SAGE Publications, 2009. pp. 287-321.

5 RUBIN, Barnett y JONES, Bruce. Prevention of violent conflict: Tasks and challenges for the United Nations. Global Governance 13. 2007. pp. 391-408.

LUND. Op. Cit. pp. 287-321.

OSLER, Fen y MALONE, David y WERMESTER, Karin. Introduction: making conflict prevention a priority. En: OSLER, Fen y MALONE, David. From reaction to conflict prevention: opportunities for the UN. Lynne Rienner Publishers, 2002. pp. 1-11. 
Por otro lado, ciertos conceptos en la literatura de prevención de conflictos carecen de un significado común. La definición de prevención de conflictos, el momento de las medidas, la simultaneidad de los diferentes tipos de acciones y los términos utilizados son las principales áreas donde existen divergencias. En primer lugar, no existe una definición ampliamente acordada del término prevención de conflictos, y tiene significados diferentes para los expertos ${ }^{8}$; tales como: gestión de crisis, diplomacia preventiva, o la incluyen en conceptos más amplios como gestión de conflictos o resolución de conflictos. En segundo lugar, algunos académicos mantienen que la prevención de conflictos es un conjunto de herramientas que deben aplicarse en cualquiera de las fases del conflicto ${ }^{9}$, mientras otros afirman que la prevención debe evitar la escalada de disputas políticas ${ }^{10}$. Por último, existen diferentes nociones sobre cómo aplicar simultáneamente las medidas estructurales y operacionales ${ }^{11}$.

Para este trabajo se entenderá como prevención de conflictos a "cualquier medida para evitar que disputas y tensiones intraestatales o interestatales escalen hacia una violencia significativa y el uso de la fuerza armada y, asimismo, para fortalecer a las partes para resolver pacíficamente sus disputas, y reducir progresivamente los problemas subyacentes que producen esas tensiones"12.

Diferentes actores emprenden esfuerzos de prevención de conflictos a nivel internacional, regional y nacional; lo que se refleja en la incorporación de iniciativas de prevención en las agendas políticas de diversos organismos internacionales ${ }^{13}$. De estos actores, las organizaciones regionales han liderado los esfuerzos en sus respectivas áreas de influencia, donde actúan conjuntamente con las Naciones Unidas o de manera independiente. Además, han adoptado estrategias de prevención de conflictos con el fin de reforzar su capacidad para

8 WALLENSTEEN, Peter y MÖLLER, Frida. Conflict prevention: methodology for knowing the unknown. Peace Papers 7, Department of Peace and Conflict Research, Uppsala University. 2003. Fecha de consulta: marzo de 2017. Disponible en: http://www.pcr.uu.se/digitalAssets/22/a_22941-f_PREVENTION__Knowing_the_ unknown.pdf

9 SCHNABEL, Albrecht y CARMENT, David. Conflict prevention: path to peace or grand illusion? UN University Press. 2003.

10 JENTLESON, Bruce. "Opportunities missed, opportunities seized: preventive diplomacy in the post-Cold war world." Carnegie Commission on Preventing Deadly Conflict series, Carnegie Corporation of New York. 1999.

11 WALLENSTEEN, Peter. Reassessing recent conflicts: direct versus structural prevention. En: OSLER, Fen y MALONE, David. From reaction to conflict prevention: opportunities for the UN system. Lynne Rienner Publishers. 2002. pp. 213-228.

12 LUND, Michael. Preventing violent intrastate conflicts: Learning lessons from experience. En: VAN TONGEREN, Paul. Searching for peace in Europe and Eurasia: An overview of conflict prevention and peacebuilding. Lienner Press. 2002. p. 117.

13 ACKERMANN, Alice. The idea and practice of conflict prevention. Journal of Peace Research 40. 2003. p. 344. 
emprender acciones preventivas de manera eficiente ${ }^{14}$. En suma, existe una creciente participación de este tipo de organizaciones en la prevención de conflictos, de acuerdo con su respectiva agenda de seguridad regional.

\section{UNASUR Y SU ROL EN LA PREVENCIÓN DE CONFLICTOS}

UNASUR es una organización internacional que busca avanzar en la integración regional en América del Sur. Esta Unión pretende construir una identidad regional basada en la historia compartida de sus miembros, los principios del multilateralismo, el derecho internacional y el respeto absoluto de los derechos humanos y los procesos democráticos ${ }^{15}$. Según su tratado, los Estados buscan la integración con el fin de lograr la inclusión social, la participación ciudadana, fortalecer la democracia y reducir las asimetrías en el marco del fortalecimiento de la soberanía y la independencia de los estados ${ }^{16}$. Desde su fundación, los miembros han sido Argentina, Bolivia, Brasil, Colombia, Chile, Ecuador, Guyana, Paraguay, Perú, Surinam, Uruguay y Venezuela.

UNASUR ha tenido algunos desarrollos significativos en comparación con otras experiencias de integración en la región. Es la primera organización que reúne exclusivamente a todas las naciones sudamericanas y ha creado espacios de diálogo político entre sus miembros. El Consejo de Jefes de Estado, el Consejo de Ministros de Relaciones Exteriores, el Consejo de Delegados y la Secretaría General son ejemplos de instituciones pioneras en Sudamérica y una sólida evidencia de un espacio para la provisión de normas, estándares y políticas regionales, en áreas distintas al comercio ${ }^{17}$. Además, la creación del Consejo Sudamericano de Defensa (CDS) y su Centro Asociado para Estudios Estratégicos de Defensa son hitos relevantes en la agenda regional de seguridad y defensa; proyectando a UNASUR como una estructura multilateral clave para la gobernabilidad de la seguridad en Sudamérica ${ }^{18}$.

\section{UNASUR y la prevención de conflictos}

El tratado constitutivo de UNASUR carece de herramientas operacionales de prevención de conflictos. La organización no cuenta con estamentos es-

14 BJORKDAHL, Annika. Conflict prevention mainstreaming: a comparison of multilateral actors. En: SCHNABEL, Albrecht y CARMENT, David. Conflict Prevention from Rhetoric to Reality: Organizations and Institutions. Lexington Books, 2004. p. 387.

15 UNASUR. Tratado Constitutivo. Brasilia, Brasil. 2008.

16 Ibíd.

17 BIANCULLI, Andrea. Latin America. En: BORZEL, Tanja y RISSE, Thomas. The Oxford Handbook of Comparative Regionalism, Oxford University Press, 2016. p. 166.

18 FLEMES, Daniel y RADSECK, Michael. Gobernanza multinivel de seguridad en América del Sur. Papers Políticos, Colombia. Vol. 17, No 1, enero-junio, 2012. p. 219. Fecha de consulta: mayo de 2017. Disponible en: http://www.scielo.org.co/pdf/papel/v17n1/v17n1a08.pdf 
pecializados ante conflictos en la región, ante lo cual la Unión ha reaccionado con diferentes métodos para prevenir la escalada de esas situaciones, buscando posicionar a la organización como una opción multilateral de prevención de conflictos ${ }^{19}$. A la fecha, los principales métodos para resolver disputas y promover el diálogo entre las partes han sido acciones de mediación; condena internacional; apoyo internacional al gobierno de turno a través de declaraciones; sanciones; establecimiento de enviados especiales y establecimiento de comisiones internacionales.

No obstante, ciertos contenidos del tratado de UNASUR y la creación de consejos sectoriales en diversas áreas, debieran considerarse como medidas estructurales de prevención de conflictos. En primer término, en el documento fundacional, se explicita entre sus principales objetivos la idea de consolidar a Sudamérica como una zona de paz ${ }^{20}$. Además, la intención de UNASUR de eliminar la desigualdad socioeconómica para lograr la inclusión social, la participación ciudadana y fortalecer la democracia ${ }^{21}$, es una declaración consistente de propósitos que reducen la probabilidad de conflictos. En segundo lugar, los propósitos y funciones de los consejos en áreas como la educación, salud, economía y finanzas, desarrollo social, infraestructura y planeamiento, asuntos electorales, energía, seguridad ciudadana, justicia, delincuencia organizada transnacional, drogas, ciencia, tecnología e innovación, cultura y en el ámbito de la defensa; es evidencia de una intención por promover políticas que cooperen a la consolidación de la paz y estabilidad en la región. Por ejemplo, uno de los objetivos del CDS es convertirse en una instancia generadora de mecanismos de gestión de conflictos y medidas de confianza mutua entre los países miembros ${ }^{22}$.

\section{CONFLICTOS INTERNOS Y EL ROL DE UNASUR}

\section{Bolivia}

El presidente boliviano Evo Morales asumió su primer periodo el año 2006, con un apoyo mayoritario de la población indígena; siendo la primera vez que un miembro de ese grupo étnico asumía la presidencia nacional. En un país donde la mayoría indígena había sido históricamente marginada y la minoría blanca ostentado el monopolio del poder, la elección del presidente Morales fue conside-

19 SANAHUJA, José y VERDES-MONTENEGRO, Francisco. Seguridad y defensa en Suramérica: regionalismo, cooperación y autonomía en el marco de UNASUR. En: Coordinadora Regional de Investigaciones Económicas y Sociales. Anuario de la Integración Regional de América Latina y el Caribe, N 10, 2014. p. 500.

20 FLEMES, Daniel y NOLTE, Detlef y WEHNER, Leslie. Una comunidad de seguridad regional en formación: UNASUR y su Consejo de Defensa. Estudios Internacionales 44, No 170 . Instituto de Estudios Internacionales, Universidad de Chile. 2011. p. 107.

21 UNASUR. Op. Cit. p. 3.

22 SANAHUJA y VERDES-MONTENEGRO. Op. Cit. pp. 497 y 513. 
rado un hito rupturista ${ }^{23}$. El principal objetivo político del nuevo líder altiplánico y del Movimiento al Socialismo (MAS) era la aprobación de una nueva constitución más favorable a su electorado. Este hecho marca el inicio de la disputa entre el gobierno central y los líderes de los departamentos de las tierras bajas orienta$\mathrm{les}^{24}$, región conocida como la "media luna" y conformada por Tarija, Beni, Santa Cruz y Pando; que además corresponden al territorio con mayor riqueza productiva del país. Esta incompatibilidad fue la causa del enfrentamiento interno y de los actos de desobediencia civil y política ${ }^{25}$ que configurarían un escenario que amenazó la estabilidad de la nación altiplánica.

La escalada del conflicto en Bolivia comenzó en enero de 2008 tras el fracaso de las negociaciones entre el gobierno nacional y los prefectos de los departamentos de las tierras bajas orientales. Los temas que configuraron esta etapa de la confrontación fueron, además del proyecto de una nueva constitución, la aspiración de mayores autonomías departamentales y la distribución de los impuestos petroleros ${ }^{26}$. Estos aspectos se interrelacionaban porque el gobierno aspiraba a una nueva constitución centralista, que no contemplaba un incremento de autonomía para las regiones orientales y les restaba beneficios a la industria petrolera; específicamente, la intención era disminuir los ingresos que esos departamentos obtenían de los impuestos sobre el petróleo y el gas ${ }^{27}$. Esta incompatibilidad llevó a que el gobierno central buscara aprobar la constitución mediante un referéndum nacional y los prefectos del este aspiraran a un proceso centrado en referendos locales. Esta confrontación provocó un serio riesgo de secesión por parte de los cuatro departamentos orientales, generando una situación inédita en la región sudamericana.

Con el fin de resolver las incompatibilidades, el Congreso Nacional aprobó en mayo de 2008 una ley que ordenó la organización de referendos revocatorios para el presidente y los prefectos en agosto de ese mismo año. El resultado de esas votaciones fue el respaldo del presidente Morales y de las autoridades regionales, en ambos casos, con mayorías claras; sin embargo, esas victorias aumentaron la tensión en el país. El 28 de agosto, el gobierno insistiendo en su

${ }^{23}$ BELLAMY, Catherine y SEGURA, Renata. Conflict prevention in Bolivia and Ecuador: The role of the international community. CIC, New York University. 2009. p. 4.

24 CABALLERO, Sergio. UNASUR y su aporte a la resolución de conflictos sudamericanos: el caso de Bolivia. Documentos de trabajo 44. Instituto de Estudios Latinoamericanos, Universidad de Alcalá. 2012. p. 18. Fecha de consulta: mayo de 2017. Disponible en: http://www20.iadb.org/intal/catalogo/PE/2012/10619.pdf

25 DIAMINT, Rut. Regionalismo y posicionamiento suramericano: UNASUR y ALBA. Revista CIDOB d'Afers Internacionals 101, 2013. Fecha de consulta: marzo de 2017. p. 65. Disponible en: https://www.cidob.org/ articulos/revista_cidob_d_afers_internacionals/101/regionalismoyposicionamientosuramericanounasuryalba UGGLA, Fredrik. Bolivia: a year of living dangerously. Revista de Ciencia Política Vol. 29. pp. 252. 2009.

27 BORDA, Sandra. Desafíos y oportunidades de la UNASUR. Documento 18, Coordinadora Regional de Investigaciones Económicas y Sociales, Buenos Aires, 2012. p. 8. Fecha de consulta: mayo de 2017. Disponible en: http://www.cries.org/wp-content/uploads/2013/07/DOC18-web.pdf 
lógica original, dispuso un referéndum nacional para aprobar la nueva constitución; provocando disturbios y resistencia civil contra la administración central en los departamentos orientales ${ }^{28}$.

Las manifestaciones rápidamente se extendieron en los departamentos orientales y multitudes de simpatizantes atacaron a partidarios del gobierno, miembros del ejército y la policía; bloquearon caminos y ocuparon oficinas estatales $^{29}$. Los partidarios del gobierno reaccionaron organizando manifestaciones en apoyo del presidente Morales; siendo una de estas acciones en el departamento oriental de Pando la que terminó con la muerte de civiles pro-gubernamentales el 11 de septiembre de $2008^{30}$. Este último acontecimiento provocó una inestable situación en los departamentos del este, que llevó al país al borde de la guerra civil $^{31}$, en un contexto de denuncias de golpe de Estado y autogolpe ${ }^{32}$.

\section{UNASUR en Bolivia}

La escalada de la confrontación interna como resultado del incidente de Pando y el aumento de la resistencia civil causó la intervención de UNASUR. EI incremento de la violencia debido a que el gobierno nacional y la oposición regional movilizaron sus bases para defender sus respectivas posiciones, influyó en la decisión de la Unión de convocar una reunión urgente de todos los presidentes sudamericanos para buscar opciones que resolvieran las incompatibilidades entre los actores y contuvieran la inestable situación ${ }^{33}$.

La presidenta de Chile Michelle Bachelet, líder pro tempore de UNASUR, convocó la "Cumbre de La Moneda" después de 48 horas del incidente entre las fuerzas progubernamentales y de oposición en Pando; y la reunión en Santiago de Chile ocurrió el 15 de septiembre de 2008. El presidente Evo Morales consideró a UNASUR como una organización legítima y confiable que podría resolver la situación interna y de esa manera asistió a la reunión para solicitar el apoyo de sus pares y la implementación de algunas medidas para abordar la situación; requerimientos que recibieron el respaldo de los gobiernos de la región. Antes del inicio de la cumbre en Santiago, los líderes de la oposición enviaron una carta a la presidenta chilena, para asistir a la reunión, exponer sus posiciones y negar

28 BELLAMY. Op. Cit. p. 5.

29 UGGLA. Op. Cit. p. 257.

30 Distintas fuentes señalan las cifras de muertes entre el rango de trece y veinte personas.

31 CABALLERO, Sergio. UNASUR a través de los ojos de los Estudios Críticos de Seguridad. Documentos de Trabajo. Instituto de Iberoamérica. Universidad de Salamanca, 2014. p. 18. Fecha de consulta: abril de 2017. Disponible en: http://biblioteca.clacso.edu.ar/Espana/ib/20161220045416/pdf_1350.pdf

32 DIAMINT. Op. Cit. p. 65.

33 MALAMUD, Carlos. 2008. La Cumbre de UNASUR en Santiago de Chile y el conflicto en Bolivia. Real Instituto Elcano. Fecha de consulta: abril de 2017. Disponible en: http://www.fes-seguridadregional.org/ images/stories/docs/4428-001_g.pdf 
las afirmaciones del gobierno de que estaban alentando un golpe de Estado en Bolivia; sin embargo, la organización regional negó la petición.

El resultado principal de la Cumbre fue la Declaración de La Moneda, que condenó los incidentes de violencia política y apoyó la legitimidad del gobierno central. Este documento expresó un rechazo a cualquier intento de golpe de Estado civil, ruptura del orden institucional y secesión de territorios ${ }^{34}$; siendo este último punto donde existía un claro consenso entre los miembros de la Unión, con el objetivo de impedir la consolidación de corrientes separatistas y evitar el riesgo de la "balcanización" del país; convirtiendo a la defensa de la integridad del territorio boliviano en uno de los puntos primordiales de la posición regional ${ }^{35}$. Por otra parte, la Declaración reconoció a dos partidos enfrentados y exigió la detención inmediata de la violencia como requisito previo para una solución política del conflicto. Otro objetivo del documento fue buscar la cooperación de ambas partes en el conflicto en el marco de un diálogo político; hecho que presionó a los líderes de los departamentos del Este para que reiniciaran las negociaciones ${ }^{36}$. En síntesis, la declaración de la Unión fue un evidente apoyo al mantenimiento del régimen de gobierno en Bolivia; estableciendo además un recurso novedoso y de alta legitimidad en el ámbito de la prevención de conflictos en la región ${ }^{37}$.

La intervención de UNASUR consideró dos iniciativas que tenían por objeto intervenir en la solución, como herramientas adicionales a la emisión de un comunicado conjunto. En primer lugar, la organización regional dispuso un enviado especial, Juan Gabriel Valdés, cuyo mandato era coordinar el diálogo entre el gobierno y la oposición. Este diplomático estuvo presente en el diálogo hasta su finalización el 20 de octubre de $2008^{38}$ logrando el compromiso de ambas partes por el proceso ${ }^{39}$. En segundo lugar, la Unión dispuso una comisión internacional y recursos humanos especiales para apoyar a Bolivia en la investigación del incidente en Pando, con el objetivo de esclarecer los sucesos y formular recomendaciones para evitar la impunidad de los probables responsables ${ }^{40}$.

34 CABALLERO. Op. Cit. p. 19.

35 SANAHUJA, José. Multilateralismo y regionalismo en clave suramericana: el caso de UNASUR, los desafíos del multilateralismo en América Latina. Pensamiento Propio 33. CRIES; Universidad de Guadalajara; Universidad Iberoamericana, 2011. pp. 139-140. Fecha de consulta: junio de 2017. Disponible en: http:// www.cries.org/wp-content/uploads/2013/07/PP33-web-25-061.pdf

ROMERO, Carlos. 2009. Bolivia: de la confrontación al pacto político. En: Del conflicto al diálogo: Memorias del acuerdo constitucional, (ed.) Romero, Carlos "et al." Fundación Boliviana para la Democracia Multipartidaria y Fundación Friedrich Ebert-Instituto Latinoamericano de Investigaciones Sociales, 2009. pp. 9-48. Fecha de consulta: mayo de 2017. Disponible en: http://library.fes.de/pdf-files/bueros/bolivien/07244.pdf 
Finalmente, como resultado de la primera iniciativa de prevención de conflictos de UNASUR y su monitoreo de la negociación entre las partes, el gobierno y los líderes de la oposición acordaron celebrar un referéndum el 25 de enero de 2009 y elecciones anticipadas el 6 de diciembre de ese mismo año ${ }^{41}$. Los hechos acaecidos post incidente en Pando demuestran que UNASUR fue el principal responsable del diálogo entre las partes y su participación fue determinante para prevenir la escalada y resolver el conflicto ${ }^{42}$. El papel de la organización en defensa de la integralidad del territorio boliviano y de la ruptura del orden democrático, fue un factor clave en la prevención de la escalada de la situación ${ }^{43}$ y una prueba de su legitimidad ante las autoridades nacionales de Bolivia y la oposición regional oriental ${ }^{44}$.

\section{Ecuador}

El periodo de gobierno del presidente Rafael Correa se inicia el año 2007 con el apoyo del movimiento político Alianza País. Este hecho culmina con un periodo de inestabilidad institucional, de permanente crisis económica, altos índices de pobreza y diversas protestas sociales ${ }^{45}$ en Ecuador. Estas circunstancias facilitaron la formación de una corriente social y política que llegó al gobierno con banderas nacionalistas, democráticas y de justicia social ${ }^{46}$.

El nuevo líder ecuatoriano y sus partidarios tenían dentro de sus principales propósitos reformar el sistema económico y reorientar la política exterior de la nación ${ }^{47}$. Este proceso se reflejó en una Asamblea Constituyente que redactó la Constitución de Montecristi, que fue aprobada con un importante apoyo ciudadano. Esta carta fundamental contiene un conjunto de demandas que resultaron en agendas de modernización y transformación del Estado ${ }^{48}$; cambios que contaron con un respaldo refrendado en cinco procesos electorales ${ }^{49}$. Sin embargo, el proceso de reformas contó con la oposición de diferentes grupos de la sociedad,

41 IHS Jane's. Bolivian constitutional referendum to go ahead. Jane's Country Risk Daily Report. 21 de Octubre 2008.

42 CABALlERO. Op. Cit. p. 5.

43 ROMERO. Op. Cit. pp. 9-48.

44 CABALLERO. Op. Cit. p. 18.

45 KERSFFELD, Daniel. El papel de la UNASUR ante los conflictos internacionales: dos estudios de caso. Revista Mexicana de Ciencias Políticas y Sociales 218. Universidad Nacional Autónoma de México. 2013. pp. 198-200.

46 ORTIZ, Santiago. 30-S: La vulnerabilidad del liderazgo de la Revolución Ciudadana y de la Institucionalidad en Ecuador. Íconos. Revista de Ciencias Sociales. 39, Facultad Latinoamericana de Ciencias Sociales-Sede Ecuador. 2011. p. 26.

47 KERSFFELD. Op. Cit. p. 198.

48 FALCONÍ, Fander y OLEAS, Julio. Reforma institucional y las secuelas del 30-S. Íconos. Revista de Ciencias Sociales N³9, Facultad Latinoamericana de Ciencias Sociales-Sede Académica de Ecuador. 2010. p. 40.

49 ORTIZ. Op. Cit. p. 27. 
principalmente los partidos políticos de oposición, algunos medios de comunicación y sindicatos.

Las circunstancias del $30-S^{50}$ del 2010 tienen su origen directo en la aprobación de la Ley Orgánica de Servicio Público, decretada con el objeto de racionalizar ese servicio ${ }^{51}$, incluyendo a la fuerza militar y policial del Estado ecuatoriano. Entre otros aspectos, esta medida legal buscaba unificar procedimientos remunerativos y ascensos, restringir bonos y otros aspectos que afectaban principalmente a los intereses de la fuerza pública ${ }^{52}$. Este hecho impulsó a miembros de la policía nacional a protestar, como medida de presión para que el presidente Correa vetara la citada ley ${ }^{53}$.

A primera hora del día 30 de septiembre, los primeros reportes de prensa señalaban que integrantes del Regimiento de la Policía Quito $N^{\circ} 1$ de la capital no estaban dispuestos a cumplir con sus servicios. De manera simultánea, ocurrieron bloqueos de calles, cierre del aeropuerto de Quito por tropas de la Fuerza Aérea; insubordinación de militares en el Ministerio de Defensa y la sublevación de la policía en el Palacio Legislativo impidiendo todo tipo de ingreso ${ }^{54}$. Estas acciones ejecutadas principalmente por la policía tenían como objetivo final amenazar la continuidad de las autoridades legítimas ${ }^{55}$.

La situación en el país requería la intervención del gobierno y sus instituciones. Fue así como el presidente ecuatoriano a las 9:30 de la mañana concurre, en compañía de algunos asesores, al cuartel del Regimiento de Policía de Quito donde se hallaban los principales elementos sublevados con el objetivo de resolver la situación ${ }^{56}$. En estas circunstancias el presidente es herido por una bomba lacrimógena y es trasladado al Hospital de la Policía, localizado al otro lado del cuartel. Desde ese momento y hasta su liberación el ejecutivo y el gabinete no tuvieron capacidad para controlar la situación y tomar decisiones, mientras que el poder legislativo estuvo paralizado ${ }^{57}$. Sin embargo, el rescate definitivo de Correa es ejecutado aproximadamente a las 21:00 por 700 militares y policías ${ }^{58}$; hecho

\footnotetext{
50 Sigla empleada para referirse al día en que ocurrió la sublevación policial.

51 FALCONÍ y OLEAS. Op. Cit. p. 37.

52 PAZ, Juan y CEPEDA, Miño. El 30-S: intento de golpe de Estado en Ecuador. Dossier Ecuador, Observatorio Latinoamericano 7, Instituto de Estudios de América Latina y el Caribe, Facultad de Ciencias Sociales, Universidad de Buenos Aires, 2011. p. 14. Fecha de consulta: mayo de 2017. Disponible en: https://drive. google.com/file/d/0Bx6HJsyAgeqPNTY5YjkwZmQtZjgxYi00YjE1LTIhZDgtOTAyY2E5OGM4MTIh/view

53 FLEMES y NOLTE y WEHNER. Op. Cit. p. 122.

54 PAZ y CEPEDA. Op. Cit. pp. 14-19.

55 ORTIZ. Op. Cit. p. 28; FALCONÍ y OLEAS. Op. Cit. p. 36.

56 Ibíd. p.15.

57 ORTIZ. Op. Cit. p. 31.

58 PAZ y CEPEDA. Op. Cit. p. 17.
} 
que culminaba una jornada de violencia que dejó un total de diez víctimas fatales 59 .

Durante este periodo, diversas fueron las reacciones de apoyo o rechazo a las acciones en curso. El presidente de la Unión General de Trabajadores y dirigentes opositores respaldaron a la sublevación policial en contra del presidente Correa $^{60}$. Por el contrario, el alcalde de Guayaquil, quien representaba la oposición al gobierno, y representantes de la Cámara de la Producción se pronunciaron en contra del movimiento golpista ${ }^{61}$. Asimismo, el jefe del Comando Conjunto declaró que las FF.AA. apoyaban al gobierno, si bien solicitaban revisar la Ley de Servicio Público ${ }^{62}$. Además, en diversas ciudades del país se desarrollaron manifestaciones de rechazo a los policías insurrectos y de apoyo al presidente ${ }^{63}$.

\section{UNASUR en Ecuador}

Las circunstancias que amenazaron la estabilidad interna de Ecuador, resultaron en una rápida reacción de UNASUR con el objetivo de adoptar acciones frente a una potencial nueva interrupción de un gobierno democrático en la región. Al recibir las primeras noticias de los hechos el presidente pro tempore de la organización Néstor Kirchner, convocó a los gobernantes de los países miembros a una reunión de emergencia en Buenos Aires, donde la Unión, junto con otras medidas, iba a adoptar un nuevo procedimiento para prevenir conflictos en Sudamérica. Entre los primeros sucesos y la reacción de la organización solo mediaron algunas horas; considerando que el mismo día 30 de septiembre los jefes y jefas de Estado iniciaron su traslado para iniciar la cumbre esa misma noche en Buenos Aires. Además, la comisión de Cancilleres dispuesta en esa misma instancia arribó a Quito solo veinticuatro horas más tarde de transcurridos los primeros incidentes.

La intervención de UNASUR en Ecuador es posible dividirla en dos instancias. Primero, la reunión extraordinaria del Consejo de Jefes de Estado de la Unión que terminó en la madrugada del 1 de octubre. El resultado fue una Declaración conjunta de los asistentes, donde se identifican algunos aspectos inéditos en la postura de UNASUR frente a este tipo de situaciones y de la cual los puntos más relevantes fueron el fuerte compromiso con la preservación de la institucionalidad democrática, el Estado de derecho y el orden constitucional en Ecuador ${ }^{64}$. Asimismo, se condenó enérgicamente el intento de golpe de Estado, indicando

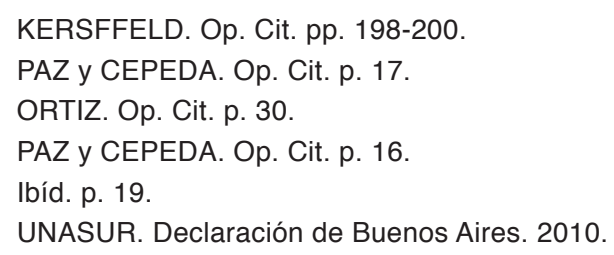


que los responsables debían ser juzgados y condenados ${ }^{65}$. Además, los líderes sudamericanos rechazaron cualquier nuevo desafío a la autoridad institucional ecuatoriana y advirtieron que en caso de nuevos quiebres del orden constitucional adoptarían medidas concretas e inmediatas, tales como: cierre de fronteras, suspensión del comercio, tráfico aéreo y de la provisión de energía, servicios y otros suministros ${ }^{66}$. Por último, acordaron adoptar en la próxima reunión de Jefes de Estado un protocolo adicional al Tratado Constitutivo de la organización que estableciera una cláusula democrática ${ }^{67}$, la que no podía ser aplicada en la presente situación, pero que se hacía evidentemente necesaria luego de la segunda situación intra-estatal que amenazaba a la región sudamericana. En síntesis, la Declaración fue interpretada como una potente señal multilateral para la defensa de la democracia en la región ${ }^{68}$.

La segunda instancia de la intervención de UNASUR fue explicitada durante la mencionada Declaración y correspondió al viaje de los Cancilleres de los países miembros a Quito, para participar en una reunión al día siguiente de los hechos. El propósito de esta comisión era expresar el pleno respaldo al presidente de Ecuador y al pueblo ecuatoriano ${ }^{69}$ y fue presidida por el presidente Correa y el ministro de Relaciones Exteriores Ricardo Patiño en el Palacio de Gobierno. En esa ocasión las intervenciones de todos los cancilleres y vicecancilleres coincidieron en la defensa de la democracia en Ecuador ${ }^{70}$. Este acto no correspondió a una instancia de mediación o negociación entre las partes en conflicto, sino que a un evento donde la Unión demostraba su apoyo y voluntad de acción ante la reciente situación que desestabilizó al Estado ecuatoriano.

El relato anterior demuestra la actitud de los líderes de UNASUR para asumir un rol de prevención para evitar una escalada de la situación en Ecuador. La consistente posición adoptada por los presidentes fue una muestra de la capacidad del bloque en situaciones de alta complejidad y de efectivo riesgo constitucional ${ }^{71}$. En este contexto, la organización regional hizo uso de dos de sus niveles de negociación; el presidencial, representado en el Consejo de Jefes de Estado bajo la mediación de la Secretaría General, y el diplomático con el Consejo de Ministros de Relaciones Exteriores ${ }^{72}$.

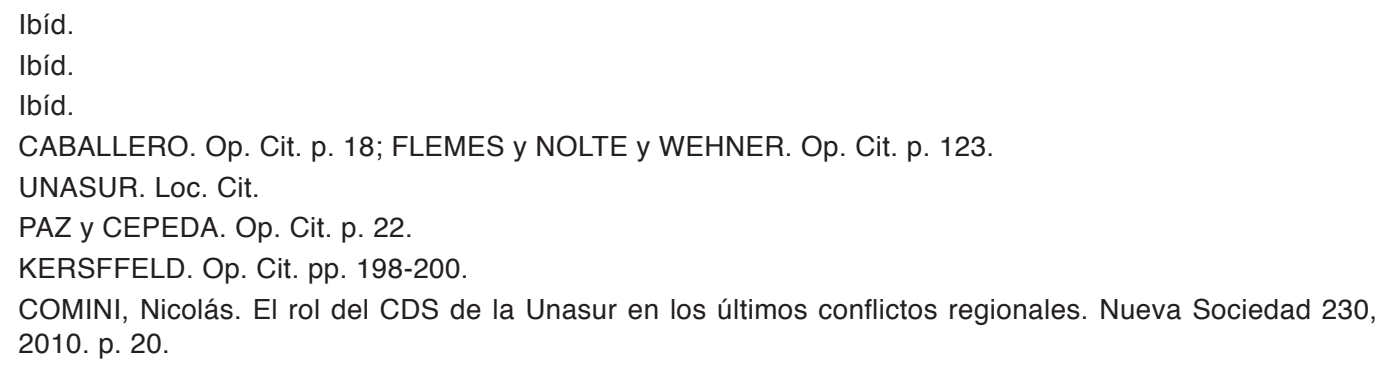




\section{Paraguay}

El inicio de la presidencia de Fernando Lugo en 2008 significó que por primera vez en sesenta años el Partido Colorado no estaba en el gobierno. El presidente Lugo, ex Obispo católico, ganó la elección nacional encabezando la Alianza Patriótica para el Cambio, con Federico Franco del Partido Liberal Radical Auténtico como vicepresidente ${ }^{73}$. El principal compromiso del presidente era emprender una reforma agraria en el país, que beneficiaría a la población campesina ${ }^{74}$. Sin embargo, antes de terminar el primer año de su periodo, el expartido gobernante y principal partido opositor, inició el primero de numerosos intentos de imputar al nuevo mandatario.

Al avanzar el gobierno del ex Obispo, la reforma agraria fue la principal incompatibilidad entre la nueva administración y la oposición ${ }^{75}$, lo que se tradujo en un estancamiento de la política agraria en la Cámara de Diputados ${ }^{76}$. Esta situación bloqueaba cualquier avance en la materia, desilusionando gradualmente a sus votantes ${ }^{77}$ y postergando las demandas de los movimientos campesinos, cuyos líderes decidieron reponer sus manifestaciones pacíficas para reclamar las propiedades en poder de los terratenientes en las zonas rurales ${ }^{78}$. Una de esas protestas terminó en un violento incidente entre las fuerzas policiales y campesinos en el distrito de Curuguaty el 15 de junio de 2012. Los hechos ocurrieron en los Campos de Morombi en medio de una acción policial para desalojar a un grupo de campesinos desde un campo perteneciente a un exsenador y empresario del agro, que había sido destinado a la reforma agraria y los manifestantes consideraban injustamente entregado ${ }^{79}$. Este enfrentamiento resultó en la muerte de seis policías y once campesinos, en una situación inédita en el país ${ }^{80}$.

Los acontecimientos en Curuguaty desencadenaron una escalada en un país ya políticamente polarizado. El incidente agregó complicaciones en una ya difícil relación entre el gobierno y la oposición respecto al movimiento

73 LÓPEZ, Magdalena. Democracia en Paraguay: la interrupción del proceso de cambio con la destitución de Fernando Lugo Méndez. Cuadernos del CENDES. № 85, 2014. p. 96. Fecha de consulta: mayo de 2017. Disponible en: http://www.scielo.org.ve/pdf/cdc/v31n85/art05.pdf

74 DUARTE, Liliana. Paraguay: A democracy consolidation process interrupted. Revista de Ciencia Política 33 , 2013.

75 KERSFFELD. Op. Cit. p. 201.

76 LLANOS, Mariana y MARSTEINTREDET, Leiv y NOLTE, Detlef. Paraguay and the politics of impeachment. Journal of Democracy 24. 2013. p. 112.

77 www.opendemocracy.net

78 DUARTE. Op. Cit. p. 307.

79 LÓPEZ. Op. Cit. p. 108.

80 ABENTE, Diego. Paraguay: un desenlace que pudo haberse evitado. En: Anuario 2012 de la seguridad regional en América Latina y el Caribe. Ed. Mathieu, Hans y Niño, Catalina. Friedrich Ebert Stiftung, 2012. p. 162. Fecha de consulta: junio de 2017. Disponible en: http://library.fes.de/pdf-files/bueros/laseguridad/07600/2012.pdf 
campesino ${ }^{81}$. Como era previsible, los partidos políticos de oposición acusaron al presidente Lugo como principal responsable del incidente ${ }^{82}$ e incluso algunos sectores lo acusaban de complicidad ${ }^{83}$. Para resolver la situación, el presidente paraguayo despidió al Primer Ministro y al jefe de la Policía Nacional; sin embargo, el nombramiento de un miembro del principal partido de oposición como nuevo Primer Ministro provocó que el presidente perdiera su débil apoyo en el Congreso ${ }^{84}$. El mayor bloque de apoyo legislativo de Lugo, el Partido Liberal, se volvió contra el gobierno y se unió al proceso de impeachment de la oposición. De esta forma, el 21 de junio de 2008, el partido Colorado lideró un juicio político contra el líder nacional en la Cámara de Diputados por mal desempeño de sus deberes ${ }^{85}$, proceso que estaba considerado en la constitución paraguaya. El argumento principal era que el presidente Lugo había mostrado un desempeño ineficiente de sus funciones y merecía la acusación ${ }^{86}$. Al día siguiente, el Senado apoyó esta decisión y depuso al presidente Lugo de su cargo. Este último estuvo en desacuerdo con el resultado del proceso, pero aceptó el veredicto ${ }^{87}$ y el vicepresidente asumió la Presidencia. Así, el líder del gobierno paraguayo era depuesto a solo nueve meses de la próxima elección presidencial.

La destitución del presidente Lugo mediante un juicio político recibió por parte de la comunidad internacional un rechazo generalizado. Si bien el juicio político de Lugo era legal y se ajustaba a las disposiciones de la Constitución paraguaya vigente desde $1992^{88}$, el proceso generó críticas porque el presidente Lugo dispuso solo de dos horas para presentar su defensa ${ }^{89}$; asimismo, solo transcurrieron 30 horas desde que la Cámara Baja anunció oficialmente sus cargos contra el presidente hasta la inauguración del sucesor de Lugo, el exvicepresidente Federico Franco. Ante este desenlace, la mayoría de los países de Sudamérica no reconocieron al nuevo presidente ${ }^{90}$, porque interpretaron el ascenso a la presidencia de este último como ilegítimo y antidemocrático ${ }^{91}$. En Asunción hubo manifestaciones de rechazo al procedimiento del Congreso para destituir

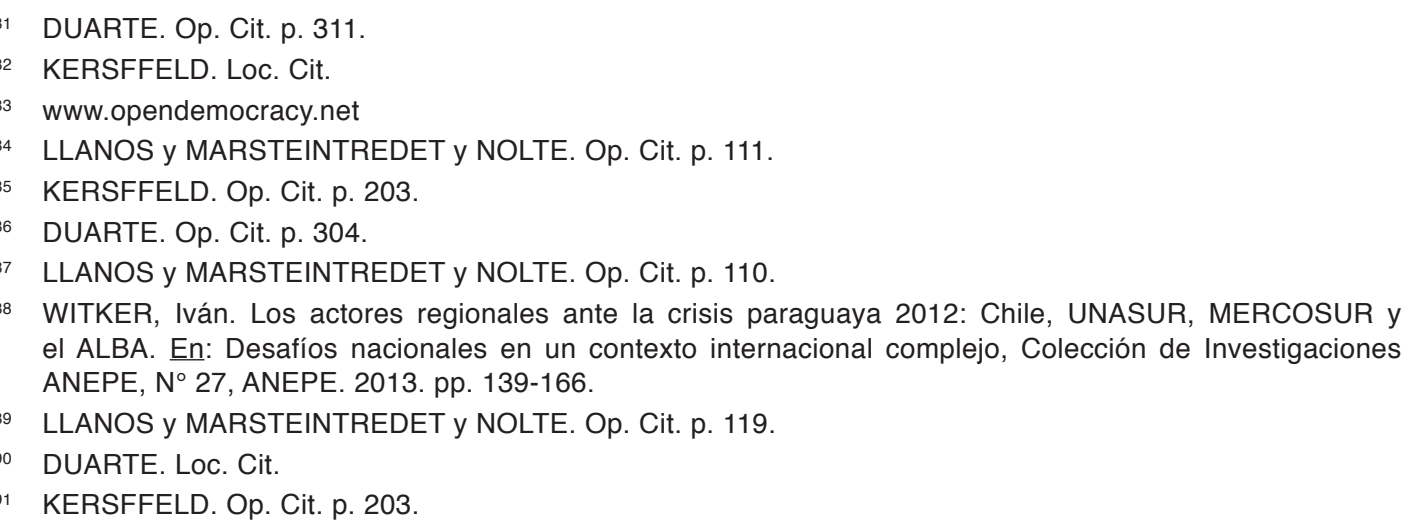


al presidente ${ }^{92}$; pero, simultáneamente, otros sectores buscaron dar legitimidad al gobierno de Federico Franco convocando marchas bajo el lema de "Paraguay soberano"93.

\section{UNASUR en Paraguay}

El rol de UNASUR comenzó antes de la destitución del presidente y se divide en dos momentos distintos. La escalada del conflicto en Paraguay se inicia el 15 de junio, seis días antes de la intervención de UNASUR. Ante los primeros acontecimientos en Asunción que hacían probable la destitución del presidente en ejercicio, los Estados miembros de la Unión reaccionaron para criticar que Lugo no tendría el tiempo suficiente para defenderse de las acusaciones que se le imputaban ${ }^{94}$. Sin embargo, la intervención de la Unión aconteció el 21 de junio de 2012, el mismo día que la oposición decidiera solucionar la incompatibilidad a través del juicio político de Lugo en la Cámara de Diputados y solo un día antes de que la oposición política enjuiciara al presidente en ejercicio, mediante un procedimiento legal en la Cámara de Senadores. De manera simultánea a la reacción de la Unión, el líder paraguayo ante la inminente resolución desfavorable a sus intereses, decidió apelar a la organización sub-regional, con la expectativa de que la acción e influencia de sus miembros detuviera el juicio político en su contra ${ }^{95}$.

Al día siguiente que la Cámara de Diputados votara en contra de Lugo, los presidentes sudamericanos enviaron a una comisión integrada por su Secretario General y ocho ministros de Relaciones Exteriores. Los enviados llegaron a Paraguay para apoyar al presidente y verificar que el Congreso respetara el proceso legal; por otra parte, buscaban intentar que el juicio político no procediera ${ }^{96}$. Como primer paso, la comisión celebró una reunión oficial con el presidente; posteriormente, y a pesar de que los líderes políticos paraguayos que encabezaban el juicio político conocían las intenciones de los enviados de la Unión, los Cancilleres lograron reunirse con el vicepresidente Federico Franco, congresistas y otras autoridades civiles para solicitar la reconsideración del proceso político y/o el debido proceso en el juicio de Lugo ${ }^{97}$.

92 DUARTE. Op. Cit. p. 304.

93 CERNA, Sarah y SOLÍS, Juan. Las tenazas del patrimonialismo paraguayo: la crisis institucional de 2012 a luz de las élites parlamentarias. Revista de las Ciencias Sociales 1, Instituto de Estudios de América Latina y el Caribe, UBA, 2012. p. 74.

94 LLANOS, Mariana y NOLTE, Detlef y WEBER, Cordula. Paraguai: Golpe ou voto de desconfiança? Revista Conjuntura Austral, vol. 3, N 14, Oct-Nov 2012. p. 12.

95 ABENTE. Op. Cit. p. 162.

96 WITKER. Loc. Cit.

97 IHS Jane's. Impeachment threat in Paraguay prompts regional concern. Jane's Intelligence Weekly. 22 de junio 2012. 
A pesar que los cancilleres lograron ser considerados como un tercer actor legítimo, la oposición política rechazó la solicitud de esos representantes relacionada con el otorgamiento de garantías procesales y democráticas en el proceso en curso ${ }^{98}$. Incluso algunos miembros del Congreso, que se reunieron con la comisión de UNASUR esa noche, declararon que la actitud de la delegación internacional parecía más un acto de presión que de mediación ${ }^{99}$. Como resultado, al día siguiente continuó el proceso político y los Senadores decidieron la deposición del presidente Lugo.

El segundo momento de la acción de la Unión se desarrolló el 29 de junio mediante una cumbre conjunta de Unasur-Mercosur en Mendoza, Argentina. En esa instancia, los miembros de la primera estimaron que se había incumplido el derecho al debido proceso y de las garantías para la defensa del presidente paraguayo, lo que implicaba una clara violación de los principios y valores que sostienen el proceso de integración sudamericano ${ }^{100}$. Por tanto, decidieron, entre otros puntos, expresar su más enérgica condena a la ruptura del orden democrático en Paraguay, suspender al país de participar en los órganos e instancias de la Unión y promover la suspensión de ese Estado en los foros de diálogo e integración política de la región ${ }^{101}$; sin imponer otras sanciones de tipo diplomático o económico. Adicionalmente, UNASUR instaló una comisión, encabezada por el ex primer ministro peruano Salomón Lerner, para monitorear los acontecimientos políticos ${ }^{102}$ que debían llevar a la normalización del orden democrático institucional en Paraguay ${ }^{103}$.

\section{ANALISIS DE LOS RESULTADOS}

Los conflictos intraestatales estudiados tienen como elementos comunes la existencia de una amenaza del gobierno central, la ausencia de terceros actores externos, la condición que alcanzaron los conflictos y, por último, la situación política reciente de los países. Primero, en todos los casos existió el riesgo de que el legítimo gobierno central no continuara con el control político o territorial del país. En la situación ecuatoriana y paraguaya, la amenaza de los actores opositores se centró en la continuidad del líder del gobierno, mientras que en el caso boliviano el riesgo provino desde una potencial secesión por parte de los líderes de las regiones orientales del país. El trabajo demuestra que en los anteceden-

98 UNASUR. Comunicado sobre la situación política en el Paraguay. Asunción, 22 junio 2012.

99 ABENTE. Op. Cit. p. 167.

100 UNASUR. Reunión extraordinaria del Consejo de Jefas y Jefes de Estado y de Gobierno. Decisión N 26/2012. Mendoza, 29 de junio de 2012.

101 UNASUR. Loc. Cit.

102 LLANOS y MARSTEINTREDET y NOLTE. Op. Cit. p. 114.

103 UNASUR. Loc. Cit. 
tes, causas y escalada de las respectivas situaciones no existió injerencia alguna de un actor externo en apoyo de alguna de las partes, situación alterada al momento de la intervención de UNASUR y otros actores regionales. En tercer lugar, ninguna de las situaciones alcanzó la condición de conflicto armado intraestatal según la definición de la Universidad de Upsala, al no producirse una cantidad de fallecidos superior a las 25 personas como producto de enfrentamientos entre las partes en el periodo de un año. Finalmente, los tres gobiernos, en distinta medida, representaban un cambio en los respectivos panoramas políticos de los países en cuestión; si bien los tres casos estaban en distintas etapas de consolidación de sus proyectos programáticos, todos simbolizaban una variación respecto a los partidos o bloques gobernantes tradicionales.

Las diferencias entre las situaciones internas analizadas se refieren a los desenlaces, las características de la escalada, el protagonismo de los gobernantes y el modo en que se resolvieron. Primero, los resultados fueron disímiles en cuanto a la solución de las incompatibilidades. Mientras que en Bolivia y Ecuador los líderes del gobierno se mantuvieron; en el caso paraguayo el presidente Lugo fue depuesto por sus opositores. En segundo lugar, en el caso paraguayo un hecho con muerte de policías y civiles marcó el inicio de la escalada, pero fue el único caso donde no existieron incidentes violentos relacionados con la incompatibilidad central que confrontó a los actores principales. Otra diferencia entre los casos es el rol de los respectivos presidentes en los momentos más complejos de las situaciones internas; en los casos de Paraguay y Bolivia los líderes actuaron en el ámbito del diálogo político; en el caso ecuatoriano, el presidente personalmente intentó detener el principal foco de sublevación policial, arriesgando su integridad física y, por ende, la dirección del gobierno central. Finalmente, en el caso paraguayo las incompatibilidades se resolvieron mediante un procedimiento de deposición considerado en la Constitución. En Bolivia la intervención de terceros actores posibilitó la solución política de las diferencias. En Ecuador, el apoyo mayoritario a la democracia y la reacción del gobierno logró debilitar el movimiento anti-gubernamental y en el transcurso de la jornada la situación comenzó a normalizarse.

El rol de UNASUR en los casos estudiados evidencia una serie de particularidades. La acción de la Unión aconteció sin estar consideradas ese tipo de acciones en la idea original de su creación, al menos de manera evidente y textual. En los tres casos UNASUR fue considerado como un actor válido para cooperar en la solución o estar presente durante la evolución y/o conclusión de las confrontaciones. Las acciones de la organización sudamericana alcanzaron un protagonismo que opacó al otrora preponderante rol de la OEA en la región; asimismo, respecto a Mercosur, instancia esta última, con un tiempo mayor de existencia. Finalmente, las intervenciones de UNASUR son interpretables como una evolución en la mirada regional para hacer frente a situaciones que pueden 
derivar en graves conflictos intra-estatales; lo que debe ser comprendido en consonancia con la norma internacional de la responsabilidad de proteger, que tiene, entre otros objetivos, prevenir situaciones que afecten la integridad de los civiles en el contexto de un conflicto interno donde el gobierno no adopta las medidas necesarias e indispensables para su protección. Estas características distintivas incrementan la relevancia del rol de UNASUR en las situaciones analizadas y permiten predecir que en el futuro la Unión podría actuar nuevamente ante iniciativas similares.

Por otra parte, las intervenciones de UNASUR evidencian ciertas similitudes y, asimismo, disparidades. Las similitudes están relacionadas con el apoyo de la Unión a los respectivos líderes de los gobiernos y la voluntad de los países integrantes de la organización para intervenir en los conflictos internos. En todos los casos, la Unión de Naciones en sus declaraciones, comunicados y acciones apoyó la legitimidad y abogó por la continuidad de los líderes nacionales en ejercicio, a pesar que las condiciones políticas internas eran disímiles. La reacción de la organización ante los tres conflictos contó con el unánime apoyo de los líderes de la región; evidenciando que las intervenciones respondieron a una sólida acción multilateral. En cuanto a los contrastes, las acciones de la Unión correspondieron a distintos tipos de procedimientos y se desarrollaron en diferentes etapas de los conflictos. Si bien las reuniones de más alto nivel ocurrieron en todos los casos, los enviados a los países afectados variaron entre un grupo de Cancilleres y un delegado especial en el caso boliviano. Además, UNASUR intervino en distintos momentos de las situaciones internas, con el objetivo de mediar entre los actores en conflicto. Fue así como en Bolivia, luego de los primeros incidentes con muertes, en Paraguay en las horas previas a que se resolviera el futuro del gobernante de turno y en Ecuador al día siguiente de que fuera amenazada la continuidad del presidente.

\section{CONLUSIONES}

El contenido del artículo describe los hechos que configuraron las situaciones intraestatales seleccionadas; específicamente, se señalaron los actores principales, las incompatibilidades existentes entre ellos y la escalada del conflicto, hasta la intervención de UNASUR como un tercer actor en la confrontación interna. Asimismo, se detallaron las acciones y procedimientos adoptados por la Unión con el objetivo de mediar entre actores opuestos y, secundariamente, impedir que un conflicto intraestatal pudiera amenazar la estabilidad de países vecinos. De esta manera, se estima logrado el propósito establecido, que además permite inferir diferencias y similitudes entre los tres conflictos, como asimismo de las acciones de prevención de la organización sudamericana. Sin embargo, las principales dificultades para lograr el objetivo fueron los escasos artículos 
académicos que describen en profundidad los conflictos en comento y las respectivas intervenciones de UNASUR. En este mismo ámbito, la breve duración y el alcance de las intervenciones de la organización sudamericana implica que la evidencia sobre esos hechos sea limitada.

Los resultados de la investigación permiten inferir la necesidad de profundizar algunos de los tópicos tratados. En primer lugar, sería importante conocer el rol que tuvieron otros organismos internacionales en los casos estudiados y la relación de sus acciones con las de UNASUR. Otro aspecto de interés sería identificar las causas que llevaron a la consecución del o los objetivos que la Unión definió al momento de decidir la intervención. Asimismo, estudiar de qué manera la orientación política de los líderes nacionales en ejercicio en el momento de las crisis estudiadas influyeron en las acciones adoptadas por la organización ante los casos descritos. Por último, investigar sobre la factibilidad de que un tercer actor haya intervenido en una etapa previa a los hechos que dieron curso a la escalada de las respectivas situaciones.

En síntesis, el trabajo demuestra que la región sudamericana periódicamente está en riesgo por situaciones políticas internas que desestabilizan a los países afectados y que amenazan la condición de zona de paz buscada por UNASUR. En este contexto, la Unión tuvo un rol relevante para cooperar en la solución de las incompatibilidades, en el apoyo al gobierno central bajo amenaza $y$, en el caso paraguayo, para corroborar que los procesos democráticos aseguraran la legítima defensa del presidente legítimo. Estas iniciativas de carácter multilateral requieren ser analizadas con una mayor profundidad para identificar lecciones aprendidas de las estrategias y herramientas utilizadas, con el objeto de enfrentar de mejor manera futuras situaciones similares en la región y mantener a Sudamérica como una región estable, donde las incompatibilidades entre los actores intraestatales se canalicen a través del diálogo y del respectivo marco constitucional. 


\section{REFERENCIAS BIBLIOGRÁFICAS}

ABENTE, Diego. Paraguay: un desenlace que pudo haberse evitado. En: Anuario 2012 de la seguridad regional en América Latina y el Caribe. Ed. Mathieu, Hans y Niño, Catalina. Friedrich Ebert Stiftung, 2012.

ACKERMANN, Alice. The idea and practice of conflict prevention. Journal of Peace Research 40, 2003.

BELLAMY, Catherine y SEGURA, Renata. Conflict prevention in Bolivia and Ecuador: The role of the international community. CIC, New York University. 2009.

BIANCULLI, Andrea. Latin America. En: BORZEL, Tanja y RISSE, Thomas. The Oxford Handbook of Comparative Regionalism, Oxford University Press, 2016.

BJORKDAHL, Annika. Conflict prevention mainstreaming: a comparison of multilateral actors. En: SCHNABEL, Albrecht y CARMENT, David. Conflict Prevention from Rhetoric to Reality: Organizations and Institutions. Lexington Books. 2004.

BORDA, Sandra. Desafíos y oportunidades de la UNASUR. Documento 18, Coordinadora Regional de Investigaciones Económicas y Sociales, Buenos Aires, 2012.

CABALLERO, Sergio. UNASUR a través de los ojos de los Estudios Críticos de Seguridad. Documentos de Trabajo. Instituto de Iberoamérica. Universidad de Salamanca, 2014.

CABALLERO, Sergio. UNASUR y su aporte a la resolución de conflictos sudamericanos: el caso de Bolivia. Documentos de trabajo 44. Instituto de Estudios Latinoamericanos, Universidad de Alcalá. 2012.

CERNA, Sarah y SOLíS, Juan. Las tenazas del patrimonialismo paraguayo: la crisis institucional de 2012 a luz de las élites parlamentarias. Revista de las Ciencias Sociales 1, Instituto de Estudios de América Latina y el Caribe, UBA, 2012.

COMINI, Nicolás. El rol del CDS de la Unasur en los últimos conflictos regionales. Nueva Sociedad 230, 2010.

DIAMINT, Rut. Regionalismo y posicionamiento suramericano: UNASUR y ALBA. Revista CIDOB d'Afers Internacionals 101, 2013.

DUARTE, Liliana. Paraguay: A democracy consolidation process interrupted. Revista de Ciencia Política 33, 2013. 
FALCONÍ, Fander y OLEAS, Julio. Reforma institucional y las secuelas del 30-S. Íconos. Revista de Ciencias Sociales № 39, Facultad Latinoamericana de Ciencias Sociales-Sede Académica de Ecuador. 2010.

FLEMES, Daniel y RADSECK, Michael. Gobernanza multinivel de seguridad en América del Sur. Papers Políticos, Colombia. Vol. 17, № 1 , enero-junio, 2012.

FLEMES, Daniel y NOLTE, Detlef y WEHNER, Leslie. Una comunidad de seguridad regional en formación: UNASUR y su Consejo de Defensa. Estudios Internacionales 44, № 170 . Instituto de Estudios Internacionales, Universidad de Chile. 2011.

IHS Jane's. Bolivian constitutional referendum to go ahead. Jane's Country Risk Daily Report. 21 de octubre de 2008.

IHS Jane's. Impeachment threat in Paraguay prompts regional concern. Jane's Intelligence Weekly. 22 de junio de 2012.

IHS Jane's. South American leaders back Morales. Jane's Intelligence Review. September 18, 2008.

JENTLESON, Bruce. "Opportunities missed, opportunities seized: preventive diplomacy in the post-Cold war world." Carnegie Commission on Preventing Deadly Conflict series, Carnegie Corporation of New York. 1999.

KERSFFELD, Daniel. El papel de la UNASUR ante los conflictos internacionales: dos estudios de caso. Revista Mexicana de Ciencias Políticas y Sociales 218. Universidad Nacional Autónoma de México. 2013.

LÓPEZ, Magdalena. Democracia en Paraguay: la interrupción del proceso de cambio con la destitución de Fernando Lugo Méndez. Cuadernos del CENDES. N 85, 2014.

LUND, Michael. Conflict prevention: Theory in pursuit of policy and practice. En: Bercovitch, Jacob "et al". Handbook of Conflict Resolution. SAGE Publications, 2009.

LUND, Michael. Preventing violent intrastate conflicts: Learning lessons from experience. En: VAN TONGEREN, Paul. Searching for peace in Europe and Eurasia: An overview of conflict prevention and peacebuilding. Lienner Press. 2002.

LLANOS, Mariana y MARSTEINTREDET, Leiv y NOLTE, Detlef. Paraguay and the politics of impeachment. Journal of Democracy 24. 2013.

LLANOS, Mariana y NOLTE, Detlef y WEBER, Cordula. Paraguai: Golpe ou voto de desconfiança? Revista Conjuntura Austral, vol. 3, № 14, Oct-Nov 2012. 
MALAMUD, Carlos. 2008. La Cumbre de UNASUR en Santiago de Chile y el conflicto en Bolivia. Real Instituto Elcano.

ORTIZ, Santiago. 30-S: La vulnerabilidad del liderazgo de la Revolución Ciudadana y de la Institucionalidad en Ecuador. Íconos. Revista de Ciencias Sociales. 39, Facultad Latinoamericana de Ciencias Sociales-Sede Ecuador. 2011.

OSLER, Fen y MALONE, David y WERMESTER, Karin. Introduction: making conflict prevention a priority. En: OSLER, Fen y MALONE, David. From reaction to conflict prevention: opportunities for the UN. Lynne Rienner Publishers, 2002.

PAZ, Juan y CEPEDA, Miño. El 30-S: intento de golpe de Estado en Ecuador. Dossier Ecuador, Observatorio Latinoamericano 7, Instituto de Estudios de América Latina y el Caribe, Facultad de Ciencias Sociales, Universidad de Buenos Aires, 2011. p.14.

ROMERO, Carlos. 2009. Bolivia: de la confrontación al pacto político. En: Del conflicto al diálogo: Memorias del acuerdo constitucional, ed. Romero, Carlos "et al". Fundación Boliviana para la Democracia Multipartidaria y Fundación Friedrich Ebert-Instituto Latinoamericano de Investigaciones Sociales, 2009.

RUBIN, Barnett y JONES, Bruce. Prevention of violent conflict: Tasks and challenges for the United Nations. Global Governance 13. 2007

SANAHUJA, José. Multilateralismo y regionalismo en clave suramericana: el caso de UNASUR, los desafíos del multilateralismo en América Latina. Pensamiento Propio 33. CRIES; Universidad de Guadalajara; Universidad Iberoamericana, 2011.

SANAHUJA, José y VERDES-MONTENEGRO, Francisco. Seguridad y defensa en Suramérica: regionalismo, cooperación y autonomía en el marco de UNASUR. En: Coordinadora Regional de Investigaciones Económicas y Sociales. Anuario de la Integración Regional de América Latina y el Caribe, $\mathrm{N}^{\circ}$ 10, 2014.

SCHNABEL, Albrecht y CARMENT, David. Conflict prevention: path to peace or grand illusion? UN University Press. 2003.

UGGLA, Fredrik. Bolivia: a year of living dangerously. Revista de Ciencia Política Vol. 29. 2009.

UNASUR. Declaración de Santiago. 2008.

UNASUR. Tratado Constitutivo. Brasilia, Brasil. 2008.

UNASUR. Declaración de Buenos Aires. 2010. 
UNASUR. Comunicado sobre la situación política en el Paraguay. Asunción, 22 junio 2012.

UNASUR. Reunión extraordinaria del Consejo de Jefas y Jefes de Estado y de Gobierno. Decisión № 26/2012. Mendoza, 29 de junio de 2012.

WALLENSTEEN, Peter. Reassessing recent conflicts: direct versus structural prevention. En: OSLER, Fen y MALONE, David. From reaction to conflict prevention: opportunities for the UN system. Lynne Rienner Publishers. 2002.

WALLENSTEEN, Peter y MÖLLER, Frida. Conflict prevention: methodology for knowing the unknown. Peace Papers 7, Department of Peace and Conflict Research, Uppsala University. 2003.

WITKER, Iván. Los actores regionales ante la crisis paraguaya 2012: Chile, UNASUR, MERCOSUR y el ALBA. En: Desafíos nacionales en un contexto internacional complejo, Colección de Investigaciones ANEPE, N²7, ANEPE. 2013.

www.opendemocracy.net

www.pcr.uu.se/research/ucdp/definitions/

www.unasursg.org 